\title{
Decision Analysis on Selection Behavior of the Self-Study Room Based on Systematic Thought
}

\author{
Wang Fu-yu ${ }^{12^{*}}$, Ye Chun-ming ${ }^{1}$, Zhang Ya-nan ${ }^{2}$ and Li Yan ${ }^{2}$ \\ ${ }^{I}$ Management School, University of Shanghai for Science and Technology, Shanghai, 200093, P.R. China; ${ }^{2}$ School of \\ Management Science \& Engineering, Anhui University of Technology, Ma Anshan, 243031, P.R. China
}

\begin{abstract}
With the rapid increase of the number of college students, the limited resources of self-study room has become more and more tense, which result in a series of bad phenomenon like grab seats. Taking a college as an example, this paper investigated the students' self-study room choice behavior by using the method of questionnaire survey. Then the game analysis on self-study room choice behavior of college students was carried out based on systematic thought. As results, the optimization strategy and suggestions about self-study room choice behavior were put forward. The results show that the analysis and improvement to self-study room choice behavior of college students can effectively improve students' self-study room selection efficiency.
\end{abstract}

Keywords: Game analysis, learning efficiency, optimization strategy, selection decision, systematic thought.

\section{INTRODUCTION}

With social competition becoming more and more intense, the enrollment scale of college is gradually expanding. The demand growth of study room and limited supply of seats to form a huge contradiction, which results in a series of bad phenomena such as robbing seat, occupying seat and brings some problems such as wasting resources [1-3]. So, how to reasonable arrangement the study hall not only can meet student's self-study, but also can save of resources, reduce the management cost, and improve the efficient of the student learning, which has been one of the hot topics in college [4-7].

For the game analysis on study room choice behavior considering the effect of learning, the researchers usually divided the study into the personal experiences learning and observational learning. The early game theorists think the vast majority of non-cooperation game theory research focused on equilibrium problems. Under the conditions of common knowledge, the rational players and their payoff function produce the Nash Equilibrium and refining solution. Because there are many problems both in theory and in empirical, the equilibrium thoughts from study evolution and imitation was positive studied. Later, researchers more focused on the individual learning process and studied the economic behavior [8-12].

Studies in psychology and economics indicate that there are different learning process and the related characteristics of the learning process. However, the game theorists have more interested in virtual game, replicator dynamics and other adaptive learning models [13-17].
In this paper, it takes the self-study room choice behavior of college students as research object, summarizes two basic learning models based on reinforcement learning and belief learning. Then, it builds the evolutionary game model about self-study room choice behavior based on systematic thought, and carries out the game analysis to the student selfstudy room choice and decision-making behaviors. Finally, it gives reasonable proposal to student study room selection and the school's study room management.

\section{EXPERIMENTAL DATA COLLECTION AND ANALYSIS}

The game analysis on self-study room choice behaviour is based on the relevant data and psychological knowledge. Therefore, the choice of research object and survey method is very important. In this paper, we need to collect many data which including the school layout, distribution map of the study room, routes diagram, the effect factors, etc. In order to reflect the effectiveness and representativeness of survey data, the paper applied the typical survey, major survey, sampling survey and case study to collect relevant data and carry out uniform survey.

\subsection{Data Table Design and Data Collect}

According to the research needs, we design three research forms, which are questionnaire on self-study room choice behaviour, statistics table of apartment student select behaviours for study room, summary table of students' select study room behaviours. These tables are shown as Tables 1-3.

\subsection{Data Analysis on Self-Study Room Choice Behaviour}

According to the research statistics data, we can see that the selection probability of self-study rooms were (from high 
Table 1. Questionnaire on self-study room choice behavior.

\begin{tabular}{|c|c|c|c|c|c|c|}
\hline Study Room & Administration Building & Teaching Building & Electric Building & Mechanical Building & Library & Ladder Classroom \\
\hline \hline Select & & & & & yes & $\begin{array}{c}\text { Good environment, } \\
\text { convenient }\end{array}$ \\
\hline Reason & & & & & Apartment: X building \\
\hline
\end{tabular}

Table 2. The study room choice survey statistics of $x$ building student.

\begin{tabular}{|c|c|c|c|c|c|c|}
\hline Study Room & $\begin{array}{c}\text { Administration } \\
\text { Building }\end{array}$ & Teaching Building & Electric Building & Mechanical Building & Library & Ladder Classroom \\
\hline \hline Number of people & 15 & 32 & 2 & 6 & 43 \\
\hline Reason & Near, fewer people & Fewer people, near & random & Fewer people & $\begin{array}{c}\text { Near, good } \\
\text { environment }\end{array}$ \\
\hline
\end{tabular}

Table 3. Summary of student study room choice.

\begin{tabular}{|c|c|c|c|c|c|c|}
\hline Study Room & $\begin{array}{c}\text { Administration } \\
\text { Building }\end{array}$ & Teaching Building & Electric Building & Mechanical Building & Library & Ladder Classroom \\
\hline \hline $\begin{array}{c}\text { Total number of } \\
\text { people }\end{array}$ & 48 & 128 & 42 & 332 & 512 \\
\hline Percentage & $4.4 \%$ & $11.6 \%$ & $3.8 \%$ & $30.2 \%$ & $46.5 \%$ & $3.5 \%$ \\
\hline
\end{tabular}

to low) library (46.5\%), mechanical building (30.2\%), teaching building (11.6\%), administration building (4.4\%), electric building (3.8\%) and ladder classroom building $(3.5 \%)$. Further, students generally remarked that the library is a first choice because it is nearest to campus apartments and has the best learning atmosphere. However, the reasons that those students choose certain study rooms are variously, especially for students who reside in different apartments. Though some students prefer the library because it is near campus housing and has the best learning atmosphere, some prefer study rooms at a farther distance because they are less crowded. Of course, some students surveyed deviate from the norm in their own habit or preference, or for other special reasons.

Because of each study room environment, congestion degree and the different distance, the students have to face much choice. Different choices lead to imbalance utilization of study room. Severe congestion is typical phenomena in every available study room, especially the library in where students are more apt to grab a seat from each other. These behaviors damage the study room's learning atmosphere and threaten the school's image as a higher-level institution. Inappropriate behavior also affects students' learning efficiency. Unsystematic study room selection, in addition to causing negative student behavior, wastes resources and creates new problems for school administrators.

\section{GAME ANALYSIS ON SELF-STUDY ROOM CHOICE BEHAVIOR BASED ON SYSTEMATIC THOUGHT}

\subsection{Introduction to Systematic Thought}

Modern systematic thought has a concentrated reflection in the philosophic thought of such philosophers as Descartes, Spinoza, Leibniz, Kant and Hegel. The first and indispensible condition of systematic thought is classification. We should use the concept of "systematic thought" to wholly and actively excavate Participants latent knowledge, realizing the communication and share of the knowledge.

\subsection{Building the Study Room Selection Model}

Based on the field survey and data analysis, the effect factors of college student's self-study room choice and decision-making behavior can be summarized as the three factors: environment, distance between study room and student dormitory, the level of congestion. Therefore, this paper focuses on these three factors to build its game model and analyze the study room game selection and decision-making behavior.

The factor of distance between study room and student apartment is quantified according to their respective geographic location and adjacency degree. The students living area was subdivided into eleven different student apartment blocks, respectively as X, B , C , D , E , F , G, H , I , J , K. 
And in order to simplify the calculation, all students will be assigned to each student apartment block, all students in each apartment block as a whole. So the game analysis about the study room choice and decision-making behavior can be seen as an about 11 player game analysis. The paper respectively marked the apartment blocks of X , B , C , D , E , F , $\mathrm{G}, \mathrm{H}, \mathrm{I}, \mathrm{J}, \mathrm{K}$ as $i_{1}, i_{2}, i_{3}, i_{4}, i_{5}, i_{6}, i_{7}, i_{8}, i_{9}, i_{10}, i_{11}$, where the character set $\mathrm{i}=\left(i_{1}, i_{2}, i_{3}, i_{4}, i_{5}, i_{6}, i_{7}, i_{8}, i_{9}, i_{10}, i_{11}\right)$.

Meanwhile, according to the site survey data, the selfstudy places on campus include administration building, teaching building, electric building, mechanical building, library and ladder classroom building. The paper respectively noted the six study room place as $a_{1}, a_{2}, a_{3}, a_{4}, a_{5}, a_{6}$. That is to say, all study room selection strategies have six, and the study room selection strategy set $\mathrm{A}=\left(a_{1}, a_{2}, a_{3}, a_{4}\right.$, $\left.a_{5}, a_{6}\right)$.

So, we can build reinforcement learning model of the students' self-study room choice behavior. Its evolution process is that if one choice gets a positive output, then this action occurrence probability will be increase in the future; if it is negative, the selection behavior occurrence probability will be decline in the future. Assuming the strategy set that the players can choose is $\mathrm{A}\left(a_{1}, a_{2} \ldots a_{\mathrm{i}} \ldots a_{\mathrm{k}}\right)$, so in the repeated game process from $\mathrm{t}$ to $\mathrm{t}-1$, the update function of the strategy is

$q^{t}\left(a_{i}\right)=\left\{\begin{array}{c}q^{t-1}\left(a_{i}\right)+\pi \\ q^{t-1}\left(a_{i}\right)_{\mathrm{i}}\end{array}\right.$

If the strength intensify comes from the average payoff of past actions, then

$q^{t}\left(a_{i}\right)=\phi q^{t-1}\left(a_{i}\right)+(1-\varphi) I\left(a_{i}, y\right) \pi$

Assume the initial intensity of strategy is exogenous, then the probability to select strategy $a_{\mathrm{i}}$ during phase $\mathrm{t}+1$ is

$$
p^{t+1}\left(a_{i}\right)=\frac{q^{t}\left(a_{i}\right)}{\sum_{i=1}^{k} q^{t}\left(a_{i}\right)}
$$

According to the value of probability, the player selects the greatest probability decisions action.

\subsection{Game Analysis on Self-Study Room Choice Behaviour}

\subsubsection{Assuming the Decision Rules}

To simplify the analysis process of the study room selection and decision-making behavior, the following assumptions were proposed: (1) each student trying to make their expected utility maximization; (2) Each student expected other students also make the same maximize of their expected utility; (3) Assuming each student have no preference in the psychological for three factors, which importance ratio is $1: 1: 1$.

\subsubsection{Calculating the Weight of Various Decision-Making Factors}

According to the above analysis, the three factors of impact study room choice behavior are environmental, congestion degree and the distance between student apartments and study room. So we can note the three property parameters for each study room as $m_{1}, m_{2}$ and $m_{3}$. Assuming the full score of each property parameters is 5 , we can give students correspondent score for every choice. The evaluation standards of self-study room environment and congestion degree are shown in Table 4.

According to the results, the score of evaluation factors $m_{1}$ and $m_{2}$ for each study room are shown in Table 5.

Due to the distance from each student apartment to each study room with the respective evaluation scores is negatively correlated, total score is 5 points. According to the measured distance for each study room to their apartment, set grade standards, can get the distance factor $m_{3}$ of evaluation matrix as shown in Table 6.

\subsubsection{Game Analysis on Study Room Selection}

Take X apartment building students choose the study room for example, the revenue of choose administration building is $T_{11}=(1 / 3) *(3+3+5)=3.67$, the revenue of choose teaching building is $T_{12}=(1 / 3) *(2+4+4)=3.33$, the revenue of choose the electrical building is $T_{13}=(1 / 3) *(3+4+3)$ $=3.33$, the revenue of choose the mechanical building is $T_{14}$ $=(1 / 3) *(1+3+4)=2.67$, the revenue of choose library is $T_{15}=(1 / 3) *(4+2+5)=3.67$, the revenue of choose the ladder classroom is $T_{16}=(1 / 3) * 8=2.67$. According to income, the

Table 4. Environmental and congestion evaluation scale table.

\begin{tabular}{|c|c|c|c|c|c|}
\hline Score & $\mathbf{5}$ & $\mathbf{4}$ & $\mathbf{3}$ & $\mathbf{2}$ & $\mathbf{1}$ \\
\hline \hline Environment & Very quiet & Quiet & Relatively quiet & General & Noisy \\
\hline Congestion Degree & uncrowded & General & A little crowded & Crowded & Very crowded \\
\hline
\end{tabular}

Table 5. The self-study room environment and congestion evaluation score sheet.

\begin{tabular}{|c|c|c|c|c|c|c|}
\hline Factors & $\begin{array}{c}\text { Administration } \\
\text { Building }\end{array}$ & Teaching Building & Electric Building & $\begin{array}{c}\text { Mechanical } \\
\text { Building }\end{array}$ & Library & Ladder Classroom \\
\hline \hline m1 & 3 & 2 & 3 & 4 & 5 & 3 \\
\hline m2 & 3 & 4 & 4 & 3 & 2 \\
\hline
\end{tabular}


Table 6. Distance scoring matrix of each apartment to the study room.

\begin{tabular}{|c|c|c|c|c|c|c|}
\hline Apartment No. & $\begin{array}{l}\text { Administration } \\
\text { Building }\end{array}$ & Teaching Building & Electric Building & Mechanical Building & Library & Ladder Classroom \\
\hline $\mathbf{X}$ & 5 & 4 & 3 & 1 & 4 & 1 \\
\hline B & 5 & 4 & 3 & 3 & 5 & 2 \\
\hline C & 4 & 3 & 2 & 4 & 4 & 3 \\
\hline D & 4 & 3 & 2 & 3 & 4 & 3 \\
\hline $\mathbf{E}$ & 4 & 4 & 4 & 5 & 5 & 4 \\
\hline $\mathbf{F}$ & 3 & 4 & 3 & 4 & 5 & 4 \\
\hline G & 3 & 4 & 4 & 5 & 5 & 4 \\
\hline H & 3 & 4 & 4 & 5 & 5 & 4 \\
\hline I & 3 & 5 & 4 & 5 & 5 & 4 \\
\hline $\mathbf{J}$ & 3 & 4 & 3 & 5 & 5 & 4 \\
\hline K & 3 & 4 & 4 & 5 & 5 & 4 \\
\hline
\end{tabular}

Table 7. Income matrix of each apartment students choose study room.

\begin{tabular}{|c|c|c|c|c|c|c|}
\hline Earnings & $\begin{array}{l}\text { Administration } \\
\text { Building }\end{array}$ & Teaching Building & Electric Building & Mechanical Building & Library & Ladder Classroom \\
\hline $\mathbf{x}$ & 3.67 & 3.33 & 3.33 & 2.67 & 3.67 & 2.67 \\
\hline B & 3.67 & 3.33 & 3.33 & 3.33 & 4 & 3 \\
\hline $\mathrm{C}$ & 3.33 & 3 & 3 & 3.67 & 3.67 & 3.33 \\
\hline D & 3.33 & 3 & 3 & 3.33 & 3.67 & 3.33 \\
\hline $\mathbf{E}$ & 3.33 & 3.33 & 3.67 & 4 & 4 & 3.67 \\
\hline $\mathbf{F}$ & 3 & 3.33 & 3.33 & 3.67 & 4 & 3.67 \\
\hline G & 3 & 3.33 & 3.67 & 4 & 4 & 3.67 \\
\hline H & 3 & 3.33 & 3.67 & 4 & 4 & 3.67 \\
\hline I & 3 & 3.67 & 3.67 & 4 & 4 & 3.67 \\
\hline $\mathbf{J}$ & 3 & 3.33 & 3.33 & 4 & 4 & 3.67 \\
\hline $\mathbf{K}$ & 3 & 3.33 & 3.67 & 4 & 4 & 3.67 \\
\hline
\end{tabular}

students in $\mathrm{X}$ apartment should select the administration building and library firstly. Similarly, the revenue of study room selection of the remaining apartments can be calculated. So the results can be shown in Table 7.

Take apartment building $\mathrm{X}$ for example, the paper analyzes the process of students choose the study room evolutionary game. The total number of the students can be hold in apartment building $\mathrm{X}$ and each study rooms are shown in Table 8

Assuming the number of students in each study room up to $80 \%$ capacity, that is the study room has reached the congestion condition, and set each strategy initial strengthen intensity is 1 , so $q^{0}\left(a_{1}\right)=q^{0}\left(a_{2}\right)=q^{0}\left(a_{3}\right)=q^{0}\left(a_{4}\right)=q^{0}\left(a_{5}\right)=$ $q^{0}\left(a_{6}\right)=1$. Assuming $80 \%$ of each apartment students go to class or self-study, then the decision making process of the students in $\mathrm{X}$ apartment building is as follows.

(1) At the first phase, $t=1$, choose $a_{1}$, then:

$q^{1}\left(a_{1}\right)=q^{0}\left(a_{1}\right)+3.67=4.67, q^{1}\left(a_{2}\right)=q^{1}\left(a_{3}\right)=q^{1}\left(a_{4}\right)=q^{1}$ $\left(a_{5}\right)=q^{1}\left(a_{6}\right)=1$.

The second choice probabilities of the students in $\mathrm{X}$ for each study room:

$p^{2}\left(a_{1}\right)=0.483, p^{2}\left(a_{2}\right)=p^{2}\left(a_{3}\right)=p^{2}\left(a_{4}\right)=p^{2}\left(a_{5}\right)=p^{2}$ $\left(a_{6}\right)=0.103$.

At this point, the total revenue of the students' decisions is $Y_{1}=7.17$.

(2) At the second phase, $t=2$, choose $a_{2}$, then: 
Table 8. The capacity of $X$ apartment and each study rooms.

\begin{tabular}{|c|c|c|c|c|c|c|c|}
\hline & $\mathbf{X}$ & $\begin{array}{c}\text { Administration } \\
\text { Building }\end{array}$ & Teaching Building & Electric Building & $\begin{array}{c}\text { Mechanical } \\
\text { Building }\end{array}$ & $\begin{array}{c}\text { Library } \\
\text { sroom }\end{array}$ \\
\hline \hline Capacity & 3000 & 800 & 3800 & 500 & 6000 & 4000 & 500 \\
\hline
\end{tabular}

Table 9. Congestion degree and pay off matrix for each self-study room after each selection.

\begin{tabular}{|c|c|c|c|c|c|c|c|}
\hline $\mathbf{t}$ & $\begin{array}{c}\text { Administration } \\
\text { Building }\end{array}$ & Teaching Building & Electric Building & $\begin{array}{c}\text { Mechanical } \\
\text { Building }\end{array}$ & Library & $\begin{array}{c}\text { Ladder } \\
\text { Classroom }\end{array}$ & \begin{tabular}{c} 
Revenue $\boldsymbol{Y}_{\mathbf{i}}$ \\
\hline \hline $\mathbf{1}$
\end{tabular} \\
\hline 2064 & 1368 & 1368 & 2882 & 4244 & 1368 & 7.17 \\
\hline $\mathbf{2}$ & 1676 & 2174 & 1000 & 4553 & 3108 & 1000 & 13.56 \\
\hline $\mathbf{3}$ & 1348 & 2176 & 808 & 5513 & 2455 & 308 & 21.13 \\
\hline $\mathbf{4}$ & 1096 & 2986 & 647 & 4502 & 3634 & 647 & 21.57 \\
\hline $\mathbf{5}$ & 933 & 3220 & 549 & 4582 & 3671 & 549 & 22.50 \\
\hline $\mathbf{6}$ & 808 & 2768 & 479 & 4644 & 4349 & 479 & 22.07 \\
\hline
\end{tabular}

$q^{2}\left(a_{1}\right)=4.67, q^{2}\left(a_{2}\right)=q^{1}\left(a_{2}\right)+3.33=4.33, q^{2}\left(a_{3}\right)=q^{2}$ $\left(a_{4}\right)=q^{2}\left(a_{5}\right)=q^{2}\left(a_{6}\right)=1$.

The third choice probabilities of the students in $\mathrm{X}$ for each study room:

$$
p^{3}\left(a_{1}\right)=0.359, p^{3}\left(a_{2}\right)=0.333, p^{3}\left(a_{3}\right)=p^{3}\left(a_{4}\right)=p^{3}
$$
$\left(a_{5}\right)=p^{3}\left(a_{6}\right)=0.077$.

At this point, the total revenue of the students' decisions is $Y_{2}=13.56$.

(3) At the third phase, $t=3$, choose $a_{2}$, then:

$q^{3}\left(a_{1}\right)=4.67, q^{3}\left(a_{2}\right)=q^{2}\left(a_{2}\right)+3.33=7.66, q^{3} \quad\left(a_{3}\right)=q^{3}$ $\left(a_{4}\right)=q^{3}\left(a_{5}\right)=q^{3}\left(a_{6}\right)=1$.

The fourth choice probabilities of the students in $\mathrm{X}$ for each study room:

$p^{4}\left(a_{1}\right)=0.286, p^{4}\left(a_{2}\right)=0.47, p^{4}\left(a_{3}\right)=p^{4}\left(a_{4}\right)=p^{4}$ $\left(a_{5}\right)=p^{4}\left(a_{6}\right)=0.061$.

At this point, the total revenue of the students decisions is $Y_{3}=21.13$.

(4) At the fourth phase, $t=4$, choose $a_{2}$, then:

$q^{4}\left(a_{1}\right)=4.67, q^{4}\left(a_{2}\right)=q^{3}\left(a_{2}\right)+3.33=10.99, q^{4}\left(a_{3}\right)=q^{4}$ $\left(a_{4}\right)=q^{4}\left(a_{5}\right)=q^{4}\left(a_{6}\right)=1$.

The fifth choice probabilities of the students in $\mathrm{X}$ for each study room:

$p^{5}\left(a_{1}\right)=0.238, p^{5}\left(a_{2}\right)=0.559, p^{5}\left(a_{3}\right)=p^{4}\left(a_{4}\right)=p^{5}\left(a_{5}\right)$ $=p^{5}\left(a_{6}\right)=0.051$.

At this point, the total revenue of the students' decisions is $Y_{4}=21.57$.

(5) At the fifth phase, $t=5$, choose $a_{2}$, then:

$q^{5}\left(a_{1}\right)=4.67, q^{5}\left(a_{2}\right)=14.32, q^{5}\left(a_{3}\right)=4.67, q^{5}\left(a_{3}\right)=q^{5}$ $\left(a_{4}\right)=q^{5}\left(a_{5}\right)=q^{5}\left(a_{6}\right)=1$.

The sixth choice probabilities of the students in $\mathrm{X}$ for each study room: $p^{6}\left(a_{2}\right)=0.623, p^{6}\left(a_{1}\right)=0.203, p^{6}\left(a_{3}\right)=p^{6}\left(a_{4}\right)=p^{6}\left(a_{5}\right)$ $=p^{6}\left(a_{6}\right)=0.043$

At this point, the total revenue of the students' decisions is $Y_{5}=22.50$.

(6) At the sixth phase, $t=6$, choose $a_{5}$, then:

$q^{6}\left(a_{5}\right)=q^{6}\left(a_{1}\right)=4.67, q^{6}\left(a_{2}\right)=14.32, q^{6}\left(a_{3}\right)=q^{6}\left(a_{4}\right)=q^{6}$ $\left(a_{6}\right)=1$.

The seventh choice probabilities of the students in $\mathrm{X}$ for each study room:

$$
p^{7}\left(a_{5}\right)=p^{7}\left(a_{1}\right)=0.175, p^{7}\left(a_{2}\right)=0.537, p^{7}\left(a_{3}\right)=p^{7}\left(a_{4}\right)
$$
$=p^{7}\left(a_{6}\right)=0.038$.

At this point, the total revenue of the students' decisions is $Y_{6}=22.07$.

Similarly, we can calculate the rest of each apartment select situation. After each time selection, the congestion degree for each self-study room and overall income of decision are shown in Table 9.

The results show that when $\mathrm{t}=7$, all study rooms on campus reached their expected degree of congestion. That is to say, in a certain extent, we can understand like that the number of students in each self-study room have reached the $80 \%$ of its capacity. So in the seventh time, the students might give up the require on study room environment and the degree of congestion when they select the study room, and they will give preference to the distance to the study room. In this time, they will choose the nearest study room from their apartment. Therefore, we can get the best strategy for each apartment students. The best strategies of study room selection are that the students in X should select these three study room places as their self-study room which is administration building, library and teaching building; the students at B should select administration buildings and libraries as their self-study room; the students in $\mathrm{C}$ should select library and administration building as their self-study room; the students in D should select library as their self- 


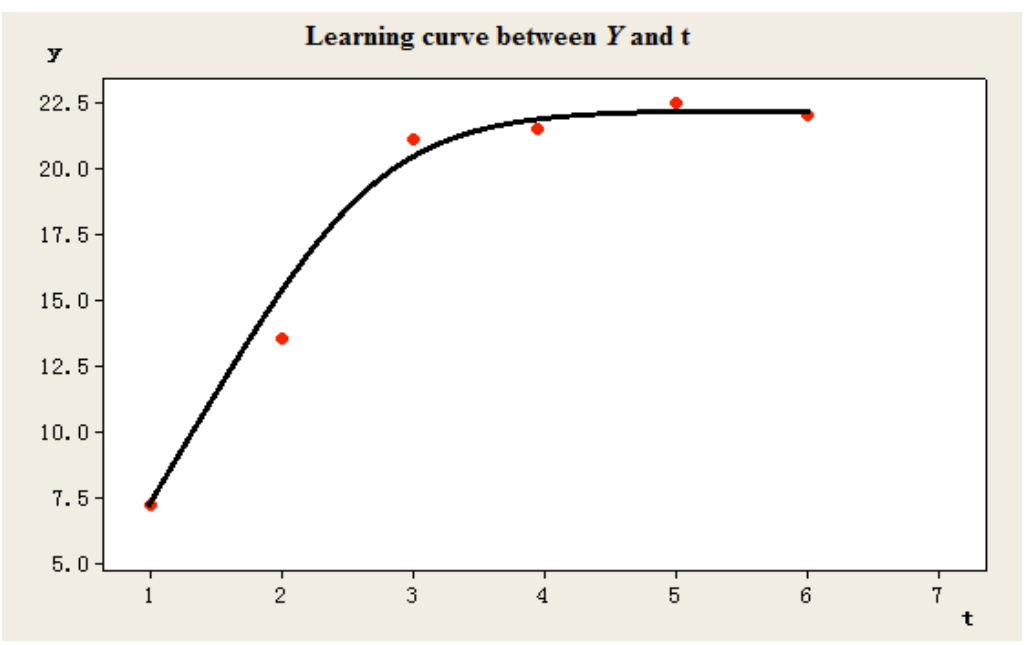

Fig. (1). The learning curve between total revenue $Y$ and game times $t$.

study room; the students in E should select the mechanical building and library as their self-study room; the students in $F$ should select library and administration buildings as their self-study room; the students in G should select library and ladder classroom as their self-study room; the students in $\mathrm{H}$ should select the library as their self-study room; the students at I should select library, mechanical building and teaching building as their self-study room; the students in $\mathrm{J}$ should select electric building and teaching building as their self-study room; the students in $\mathrm{K}$ should select the library and mechanical building as their self-study room.

\section{THE BENEFIT ANALYSIS OF DECISION SET BASED ON THE EXPERIENCE CURVE}

According to Table 9, each apartment's students select their strategy assembles after gaming to gain overall income $Y_{\mathrm{i}}$. The Experience Curve in relation to students' overall income $Y$ and gaming times $t$ can be drawn to represent the dynamic relationship between them. After the game analysis processing, the scattered point coordinates between $Y$ and $t$ are obtained: $(1,7.17),(2,13.56),(3,21.13),(4,21.57),(5$, $22.50),(6,22.07)$. According to these coordinate points, we can draw the coordinate scatter diagram about total income $Y$ and Game times $t$ by using MATLAB. Next, according to the curve fitting principle, make as many points as possible fall on the curve, and make these points are distributed on both sides of the curve for balance, the fitting curve between the total income $Y$ values and game times $t$ can be drawn in Fig. (1).

Fig. (1) shows that the relationship curve between the total revenues $Y$ and times $t$ corresponds to the knowledgelearning curve shape of learning effect. The game of student study room selection ultimately produces a horizontal line, that is, the game arrives at dynamic stabilization. The practical significance of this is that after a certain number of selection iterations, the total income of the students selecting certain study rooms reaches a steady value in which each decision maker obtains satisfactory revenue.

\section{CONCLUSION AND FUTURE DEVELOPMENTS}

Through investing the college students' select behavior for self-study room and data analysis, this paper builds a reinforcement learning model of students select study room behavior based on systematic thought, and executes game analysis of self-study room selection and decision-making under the condition of taking the study room environment, study room congestion and the distance between study room and dormitories as decision factors, The results show all students select the study room game is a dynamic processing, and with the increase game times, the revenue also increased, but eventually tends to a horizontal line, that is reached a steady state. That is, each decision makers have reached a related satisfactory income; the corresponding strategy is the optimal strategies in this state.

At this time, there are some issues in this paper can be further research and development. For example, in order to simplify the calculation, the paper only considers the environment, congestion and distance factors. In addition, during the analysis processing of the study room select behavior, the players assumed to be rational people, but haven't considered a part of special group, these special groups to select study room choice depends on personal preference or male and female friends' factors, and without considered the distance, the environment, the congestion factors effect in study room.

\section{ABOUT THE AUTHORS}

First Author Wang Fu-yu was born in Henan Province, China, in 1977 . He is currently an associate professor at Anhui University of Technology, Anhui, China. He obtained a first class Bachelor's degree in 1999 and a Master's degree in 2005 from China University Of Petroleum, Shandong, China. And he's studying for his doctorate at University of Shanghai for Science and Technology, Shanghai, China. His research interests include Industrial Engineering and Intelligent Optimization.

Second Author Ye Chun-Ming was born in Anhui Province, China, in 1964. He is currently a professor and doctoral tutor at University of Shanghai for Science and Technology, Shanghai, China. His research interests include Industrial Engineering, Intelligent Optimization and Production Scheduling.

Third Author Zhang Ya-nan was born in Anhui Province, China, in 1991 . He is currently a graduate student at Anhui University of Technology, Anhui, China. He received 
his BEng degree in Industrial Engineering from Anhui University of Technology in 2013. His research interests include Industrial Engineering and Intelligent Optimization.

Fourth Author Li yan was born in Anhui Province, China, in 1984. She is currently a lecturer at Anhui University of Technology, Anhui, China. She received her BEng degree in Industrial Engineering from Anhui University of Technology in 2008. Her research interests include Industrial Engineering and Game Analysis.

\section{CONFLICT OF INTEREST}

The authors confirm that this article content has no conflict of interest.

\section{ACKNOWLEDGEMENTS}

This research is supported by the National Natural Science Foundation of China (No. 71271138), and the Humanities and Social Sciences Youth Fund of Ministry of Education (No. 14YJC630119), and the Major Project of Humanities and Social Sciences of the Education Department of Anhui Province (No. SK2014ZD016).

\section{REFERENCES}

[1] Y.J. Sun, X.X. Yu, "Game analysis and countermeasures of occupancy seat on university library", University of Shanghai for Science and Technology, vol. 32, no. 6, pp. 573-575, 2010.

[2] Q.Z. Zeng, M.Q. Li, "Dynamic game analysis of occupancy seat on the university library," Sci-Tech Information Development \& Economy, vol. 22, no. 19, pp. 47-48, 2012.

[3] B. Sun, "Game Analysis and Countermeasures discussion of occupancy seat on university library," Information Development \& Economy, vol. 20, no. 27, pp. 41-43, 2010.

[4] K. Xu, "Economics thinking of occupancy seat on study room," Business, vol. 25, no. 11, pp. 106-106, 2013.
[5] D. Han, Y. Shi, W. Wang, Y. Dai "Research on multi-level association rules based on geosciences data," Journal of Software, vol. 8, no. 12, pp. 3269-3276, 2013.

[6] L.W. Pan, Y.L. Wu, "Game model and optimization under combined cooperation supervision and financial institutions," Statistics and Decision, no. 13, pp. 52-55, 2013.

[7] F. Luo, Y. Zhu, "Evolutionary game analysis on auditing collusion," Journal of Applied Sciences, vol. 13, no. 21, pp. 4759-4763, 2013.

[8] B. Wang, Q. Li, "Game analysis of the multi-stakeholder in concession toll road," Statistics and Decision, no. 16, pp. 44-47, 2013.

[9] Y.F. Qu, H.M. Wang, "Game analysis of water pollution control strategy selection on water district diversion," Statistics and Decision, no. 5, pp. 58-62, 2012.

[10] Y. Guo, C, Wang, Y. Feng, "The moderating effect of organizational learning culture on individual motivation and ERP system assimilation at individual level," Journal of Software, vol. 9, no. 2, pp. 365-373, 2014

[11] H.M. Fan, J.S. Li, "Symbiotic cooperative game analysis on Manufacturers in recycling of industrial wastes," Applied Mechanics and Materials, vol. 295, pp. 1784-1788, 2013.

[12] Z.Q. Dong, "Rational Boundaries: The Unity of Game Theory and Behavioral Science," Gezhi Press: Shanghai, 2011.

[13] J. Sun, J. Lin, Y. Qian, "Game-theoretic analysis of competitive agri-biomass supply chain," Journal of Cleaner Production, vol. 43, pp. 174-181, 2013.

[14] T. Martin, A. Aghababyan, J. Pfaffman, J. Olsen,, S. Baker,, P. Janisiewicz, C. P. Smith, "Nanogenetic learning analytics: Illuminating student learning pathways in an online fraction game," Proceedings of the $3^{\text {rd }}$ International Conference on Learning Analytics and Knowledge ACM, pp. $165-169,2013$.

[15] Y.Z. Wang, "Analysis for network attack-defense based on stochastic game model," Chinese Journal of Computers, vol. 33, no. 9, pp. 1748-1762, 2010.

[16] V. Wangenheim, C. Gresse, R. Savi, "SCRUMIA — an educational game for teaching SCRUM in computing courses," Journal of Systems and Software, vol. 86, no. 10, pp. 2675-2687, 2013.

[17] S. Gregory, "Implications of a multidisciplinary students' computer game design project," Journal of Computers, vol. 8, no. 7, pp. 1836-1840, 2013.

Received: September 16, 2014

Revised: December 23, 2014

Accepted: December 31, 2014

(C) Fu-yu et al.; Licensee Bentham Open.

This is an open access article licensed under the terms of the Creative Commons Attribution Non-Commercial License (http://creativecommons.org/licenses/by-nc/3.0/) which permits unrestricted, non-commercial use, distribution and reproduction in any medium, provided the work is properly cited. 